\title{
Clinical trials in acute severe asthma: are type II errors important?
}

\author{
M J WARD \\ From the Departments of Tuberculosis and Chest Diseases and Clinical Pharmacology, Llandough Hospital, \\ Penarth, Glamorgan
}

ABSTRACT Many studies in acute severe asthma have had low power. Fifteen randomised double blind studies investigating the treatment of acute severe asthma published during 1974-84 were analysed for power and $95 \%$ confidence limits. Twelve studies failed to detect a significant difference $ᄋ$ in bronchodilatation produced by two treatments and reported the treatments to produce equal $\vec{a}$ effect. Each study had, however, less than a $60 \%$ probability of detecting a true $25 \%$ difference in $z$ bronchodilatation.

The surprisingly few double blind studies comparing treatments in acute severe asthma have reported disparate results. The treatments studied have included corticosteroids, sympathomimetics, and aminophylline. The place of corticosteroid treatment is unclear. Many studies have claimed that no benefit follows but Macdonald and others have recommended the use of corticosteroids. ${ }^{12}$ While there is no doubt that sympathomimetic drugs are life saving in severe asthma there is argument about the best route of administration. Theoretically sympathomimetics such as salbutamol might be expected to produce better bronchodilatation when given parenterally than by inhalation, but reports suggest that this is not the case. ${ }^{34}$ Investigators have also made varying claims about aminophylline, some reporting it to be extremely useful, others preferring not to use it. ${ }^{56}$

How may these differing statements be explained, and how should we investigate the treatment of severe asthma in the future? Trials so far have concentrated on tests of statistical significance. Although the familiar expression $p<0.05$ means that the observed difference between treatments could arise by chance in less than one in 20 trials (type I error), a nonsignificant difference between treatments does not mean that the treatments produce the same result. Whether trials reporting no difference between treatment regimens were ever likely to demonstrate a difference (their power) depends on their design and the number of patients studied. A recent review of 71

Address for reprint requests: Dr M J Ward, Llandough Hospital, Penarth, Glamorgan.

Accepted 7 July 1986 studies with negative results showed that because of low power most had a considerable chance of not $\vec{\bullet}$ being able to detect a clinically useful difference $\stackrel{\circ}{\circ}$ between treatments (type II error). ${ }^{7}$

Many workers have compared two treatments in severe asthma and on finding "no significant" difference $(p>0.05)$ between the results of treatment have concluded that the treatments produce equal $\stackrel{\circ}{\mathbb{D}}$ effect. To assess the outcome of reported trials in severe asthma I have analysed double blind randomised studies comparing one treatment with another in terms of the statistical significance of any differences observed, $95 \%$ confidence limits for the results of treatment, and the power of the study to detect a real difference between treatments.

\section{Methods}

Twenty two trials investigating the use of corticosteroid drugs or intravenous bronchodilators in the treatment of acute severe asthma published during 1974-84 were identified through Index Medicus. Fifteen were randomised, controlled, and double blind and the results of these have been analysed. In each $\tilde{N}$ study the bronchodilator response, measured by $N$ increase (mean and standard deviation) in peak $N$ expiratory flow rate (PEF) or $\mathrm{FEV}_{1}$, was noted along with the study size and level of significance recorded in the paper. One study reported PEF and FEV ${ }_{1}$ and $\stackrel{\circ}{C}$ both were analysed.

If a trial reports no significant difference between treatments $(\mathrm{p}>0.05)$ then it is necessary to ask whether the trial would have been able to detect a $\underset{\mathbb{D}}{ }$ difference, and what degree of difference would be $\frac{\stackrel{\rho}{\Phi}}{\mathbb{D}}$ clinically relevant. The percentage increase in bron- $\square$ 
chodilatation produced by each treatment was calculated and the difference noted. The power of the studies to detect differences in bronchodilator response of $25 \%$ and $50 \%$ was calculated (fig 1); both of these values were decided arbitrarily as being levels that would have practical relevance. In all cases "percentage difference in bronchodilatation" refers to the percentage increase from baseline produced by one treatment minus the percentage increase from baseline produced by another.

An operating characteristic curve was drawn for each study, based on the description of Freiman. ${ }^{7}$ The value of $\beta$ (the probability of making a false negative or type II error) was calculated on the assumption that the level of statistical significance with a two tailed test was $\alpha=0.05$. A typical curve is shown in figure 1 . In this case the total number of patients studied was 14 . The mean PEF rose with intravenous salbutamol from 86 to $124 \mathrm{~min}^{-1}$ - that is, by $381 \mathrm{~min}^{-1}$ (an increase of $44 \%$ ). The SD of changes between subjects was $601 \mathrm{~min}^{-1}$. Nebulised salbutamol produced an increase from 82 to $1331 \mathrm{~min}^{-1}$ that is, $511 \mathrm{~min}^{-1}(62 \%), \mathrm{SD}=50$. The difference between treatments was not significant and it was concluded that the treatments produced equal effect.

On the basis of the nomogram described by Altman, ${ }^{8} \mathrm{SD}$ and $\mathrm{N}$ are used to calculate the probability $(1-\beta)$ of detecting differences (D) between treatments of 10 to $1001 \mathrm{~min}^{-1}$. In the curve values of

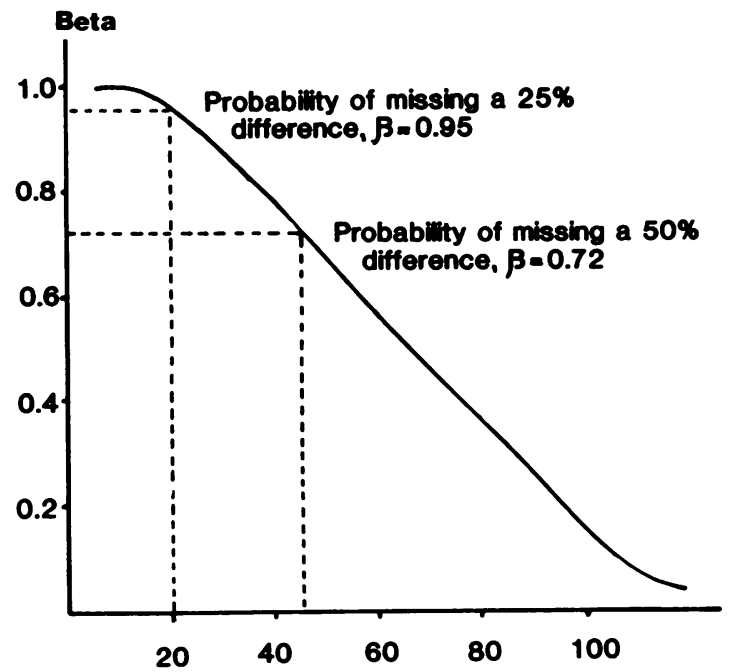

\section{Difference in PEF $\left(1 \mathrm{~min}^{-1}\right)$}

Fig 1 Operating characteristic of a representative trial.

$D$ are related to the vertical scale of $\beta$-that is, the probability of making a false negative error.

Percentage difference between treatments was calculated as follows. Nebulised treatment produced a $44 \%$ increase in PEF and for intravenous treatment

Table 1 Probability of detecting a real difference between treatments of $25 \%$ and $50 \%(1-\beta)$ in trials comparing treatments in acute severe asthma

\begin{tabular}{|c|c|c|c|c|}
\hline Description of trial & $\begin{array}{l}\text { Value of } I-\beta \text { for } \\
25 \% \text { difference } \\
\text { between treatments }\end{array}$ & $\begin{array}{l}\text { Value of } 1-\beta \text { for } \\
50 \% \text { difference } \\
\text { between treatments }\end{array}$ & $\begin{array}{l}\text { Actual } \\
\text { difference } \\
\text { reported (\%) }\end{array}$ & $\begin{array}{l}\text { No of patients studied } \\
\text { and assessment } \\
\left(P E F \text { or } F E V_{1}\right)\end{array}$ \\
\hline $\begin{array}{l}\text { Hydrocortisone/placebo } \\
\text { Corticosteroid/placebo }^{10} \\
\text { Hydrocortisone/placebo }^{11}\end{array}$ & $\begin{array}{l}0 \cdot 4 \\
0 \cdot 6 \\
0 \cdot 46\end{array}$ & $\begin{array}{l}>0.9 \\
>0.9 \\
>0.9\end{array}$ & $\begin{array}{l}5 \\
1 \\
6\end{array}$ & $\begin{array}{l}19 \text { (PEF) } \\
45\left(\mathrm{FEV}_{1}\right) \\
38\left(\mathrm{FEV}_{1}\right)\end{array}$ \\
\hline $\begin{array}{l}\text { Methylprednisolone/high } \\
\text { dose/low dose } \\
\text { Hydrocortisone/placebo }^{13}\end{array}$ & $\begin{array}{l}0.5 \\
0.3\end{array}$ & $\begin{array}{r}>0.9 \\
0.8\end{array}$ & $\begin{array}{l}15 \\
60\end{array}$ & $\begin{array}{l}16\left(\mathrm{FEV}_{1}\right) \\
20\left(\mathrm{FEV}_{1}\right)\end{array}$ \\
\hline $\begin{array}{l}\text { Salbutamol intravenous/ } \\
\text { nebulised }\end{array}$ & $\begin{array}{l}0.05 \\
0 \cdot 15 \\
0.5\end{array}$ & $\begin{array}{r}0.3 \\
0.5 \\
>0.9\end{array}$ & $\begin{array}{r}18 \\
5 \\
24\end{array}$ & $\begin{array}{l}14 \text { (PEF) } \\
20(\text { PEF) } \\
14\left(\text { FEV }_{1}\right)\end{array}$ \\
\hline $\begin{array}{l}\text { Salbutamol/aminophylline } \\
\text { Salbutamol/aminophylline } \\
\text { Isoprenaline/aminophylline }^{6}\end{array}$ & $\begin{array}{l}0 \cdot 3 \\
0 \cdot 1 \\
0 \cdot 5\end{array}$ & $\begin{array}{r}0.7 \\
0.3 \\
>0.9\end{array}$ & $\begin{array}{l}27 \\
66 \\
41\end{array}$ & $\begin{array}{l}13 \text { (PEF) } \\
20(\text { PEF) } \\
32\left(\text { FEV }_{1}\right)\end{array}$ \\
\hline $\begin{array}{c}\text { Adrenaline/adrenaline } \\
+ \text { aminophylline }{ }^{16}\end{array}$ & $0 \cdot 5$ & $>0.9$ & 1 & 51 (PEF) \\
\hline $\begin{array}{l}\text { Isoprenaline/isoprenaline } \\
+ \text { aminophylline }{ }^{18}\end{array}$ & $0 \cdot 6$ & $>0.9$ & 9 & $102\left(\mathrm{FEV}_{1}\right)$ \\
\hline $\begin{array}{l}\text { Salbutamol/salbutamol } \\
+ \text { aminophylline }{ }^{17}\end{array}$ & 0.4 & $>0.9$ & 16 & 39 (PEF) \\
\hline $\begin{array}{l}\text { Salbutamol/salbutamol } \\
+ \text { aminophylline } \\
\text { Adrenaline/adrenaline }\end{array}$ & 0.35 & 0.9 & 40 & $15\left(\mathrm{FEV}_{1}\right)$ \\
\hline+ aminophylline ${ }^{19}$ & 0.7 & $>0.9$ & 54 & 60 \\
\hline
\end{tabular}


to produce $25 \%$ more bronchodilatation it would have to increase the PEF by $69 \%$ : an increase of $591 \mathrm{~min}^{-1}$, which means a difference of $211 \mathrm{~min}^{-1}$ from that produced by nebulised treatment alone.

This example shows that the study design used would result in a $95 \%(\beta=0.95)$ probability of a conclusion of no significant difference when the actual difference was $211 \mathrm{~min}^{-1}$ (a $25 \%$ difference between treatments) and a $72 \%$ probability of showing no difference when the actual difference was $421 \mathrm{~min}^{-1}$ (a $50 \%$ difference between treatments).

Ninety five per cent confidence limits were also determined on the basis of the difference between mean responses cited, the standard deviation, and the number of patients studied.

\section{Results}

\section{TRIALS COMPARING CORTICOSTEROID WITH PLACEBO}

There were five studies of the use of corticosteroids in severe asthma. Four of these were unable to detect a statistically significant benefit from the treatment..$^{9-12}$ These studies, however, all had less than a $60 \%$ (power $0.3-0.6$ ) probability of detecting $25 \%$ more bronchodilatation in those treated with corticosteroid. None of the trials would have been likely to miss a true $50 \%$ difference in bronchodilatation caused by the treatments (table 1). The $95 \%$ confidence limits for the studies are shown in figure 2. The four negative studies, being unable to detect a significant benefit from corticosteroid treatment, have limits crossing the midline zero point. Four of the five studies, however, reported more bronchodilatation in those treated with corticosteroid but only one recorded a statistically significant difference. ${ }^{13}$ In this case the $95 \%$ confidence limits lie in favour of steroid treatment and do not cross the zero line. The power of this study was, however, no greater than the others, its significance being related only to the large difference in response seen.

\section{COMPARISONS OF INTRAVENOUS AND}

NEBULISED SYMPATHOMIMETIC TREATMENT

Two randomised double blind studies have compared nebulised and intravenous salbutamol. ${ }^{414}$ Neither study detected a significant difference between treatments. Examination of the PEF data in the studies, however, shows that they had less than a $50 \%$ (power $0.3,0.5$ ) probability of being able to detect a true $50 \%$ difference in increase in PEF produced by the treatments. One study also reported the results in terms of FEV ${ }_{1}$ and the power of this study to detect a true $25 \%$ difference was $0 \cdot 5$. It had little probability of missing a $50 \%$ difference in bronchodilatation (table 1).

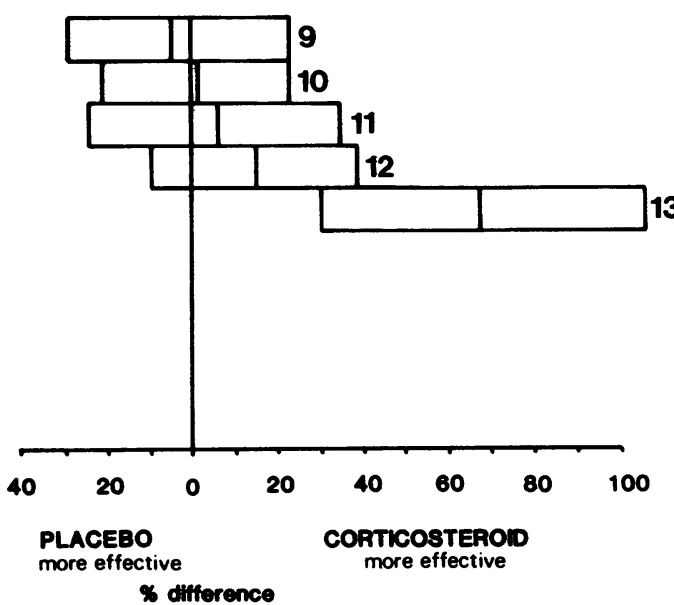

Fig 2 Nintey five per cent confidence limits for the five trials of corticosteroids in acute severe asthma. The vertical bar at the centre of each interval indicates the reported percentage difference in treatments. The true difference has a $95 \%$ chance of lying somewhere between the outer bars.

The $95 \%$ confidence limits are shown in figure 3 . Although all cross the midline, the limits are wide and substantial differences in favour of intravenous treatment are still possible.

TRIALS COMPARING AMINOPHYLLINE ALONE WITH A SYMPATHOMIMETIC ALONE

Three randomised controlled trials have compared

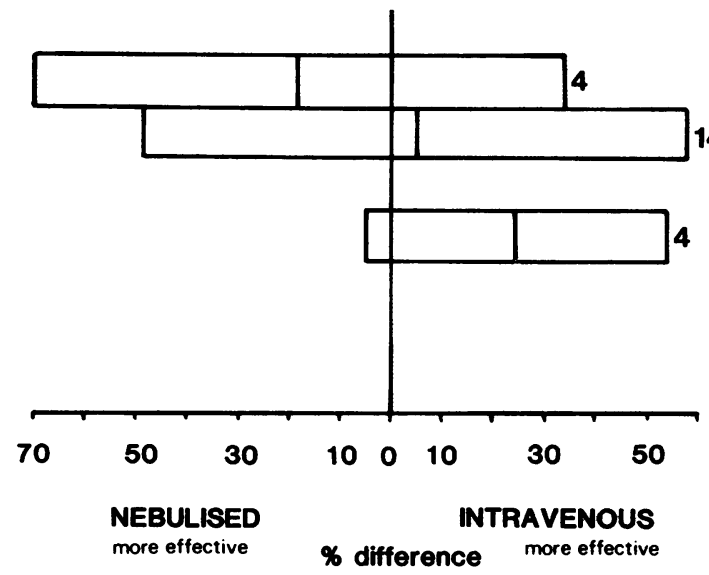

Fig 3 Nintey five per cent confidence limits for the trials of intravenous and nebulised salbutamol in severe asthma. The top two bars represent PEF data, and the other refers to $F E V_{1}$. (See note about confidence limits and the vertical bar in fig 2.) 


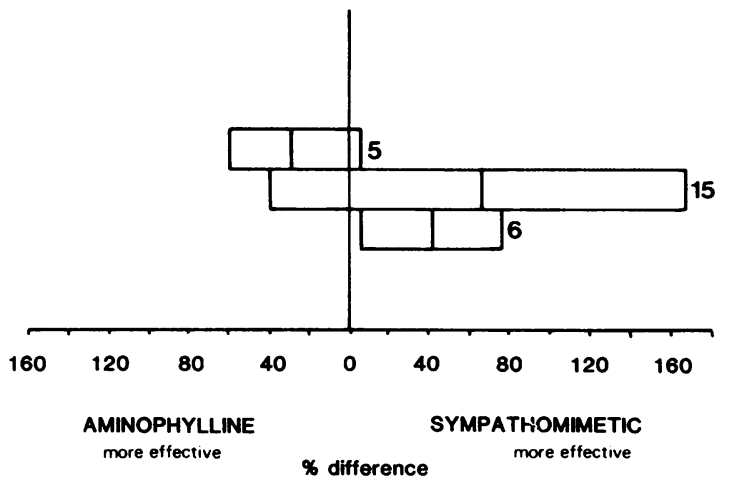

Fig 4 Nintey five per cent confidence limits for the trials concerned with the bronchodilatation produced by intravenous aminophylline and by a sympathomimetic ( $\beta$ agonist) drug. (See note about confidence limits and the vertical bar in fig 2.)

either salbutamol or isoprenaline with aminophylline. ${ }^{5615}$ In two no difference was reported between treatments but both of these had a large type II error, having less than a $30 \%$ (power $0 \cdot 1,0.3$ ) probability of detecting a true $25 \%$ difference in response to the treatments (table 1). The third study reported significantly more bronchodilatation in those treated with inhaled isoprenaline (fig 4).

\section{COMPARISON OF SYMPATHOMIMETIC DRUGS}

USED ALONE AND WITH AMINOPHYLLINE

Five randomised controlled trials have measured bronchodilatation following a sympathomimetic given alone or in combination with aminophyl-

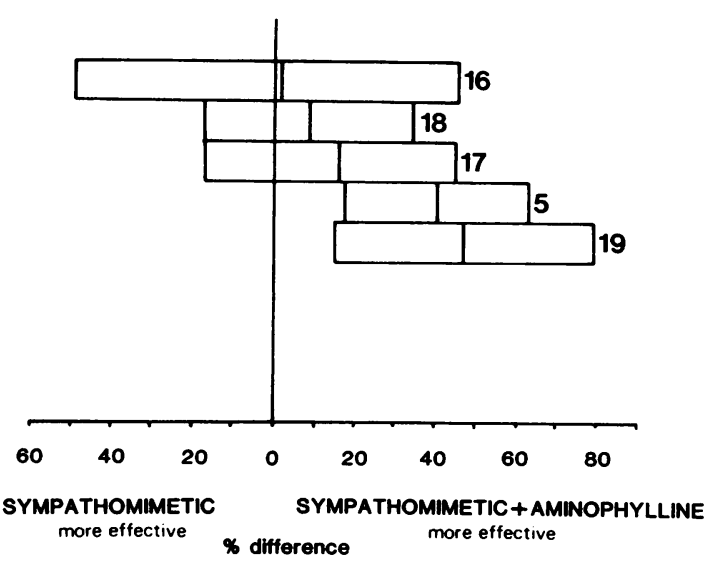

Fig 5 Nintey five per cent confidence limits for the trials of aminophylline added to a sympathomimetic drug ( $\beta$ agonist or adrenaline). (See note about confidence limits and the vertical bar in fig 2.) line. ${ }^{516-19}$ The sympathomimetic varied in the studies and two used intravenous salbutamol, one inhaled isoprenaline, and two subcutaneous adrenaline.

These trials had less than a $70 \%$ (power $0.35-0.7)$ chance of detecting a $25 \%$ difference in bronchodilatation (table 1). All had high probability of being able to detect a $50 \%$ difference between treatments. Two studies reported a clear benefit from using aminophylline with salbutamol or adrenaline (fig 5).

\section{Discussion}

In the treatment of severe asthma it is reasonable to suppose that a difference of $25 \%$ in the degree of bronchodilatation produced by two treatments would be clinically useful. Twelve of 15 studies in severe asthma have been unable to detect differences in treatment and it has been concluded that the treatments produce equal effect. The failure to attain a level of statistical significance, however, does not necessarily mean that two treatments being compared are identical. The 12 studies had less than a $60 \%$ probability of detecting a true $25 \%$ difference in treatments.

There has been much debate concerning the use of corticosteroids in severe asthma and, although the studies reported no benefit from the treatment, it is clear that they had large type II error and may have been unable to detect a clinically useful difference. Although differences were not statistically significant, examination of the $95 \%$ confidence limits (fig 2 ) shows the effect of corticosteroid treatment to be mostly in favour of treatment. This, in addition to the results in favour of corticosteroids in retrospective studies, supports the continued prescription of corticosteroids in severe asthma.

Editorial advice that in severe asthma nebulised salbutamol is as good as intravenous may be incorrect. ${ }^{20}$ There have been few controlled studies on this subject and analysis of published results shows a large type II error, so that clinically useful differences in the effects of treatment might not have been detected.

Analysis of the results of studies comparing intravenous aminophylline alone with a sympathomimetic ( $\beta$ agonist or adrenaline) shows one study with clear $95 \%$ confidence limits in favour of salbutamol (fig 4). With regard to studies using aminophylline and sympathomimetics (fig 5), these all report more bronchodilatation with the combination, two studies having $95 \%$ confidence limits clear of the zero line. Two of these studies, however, used adrenaline as the sympathomimetic instead of a more powerful selective $\beta$ agonist like salbutamol. The place of aminophylline remains controversial. There is more evidence in favour of adding aminophylline to a $\beta$ agonist than using aminophylline alone (figs 4 and 5). Whether a larger dose of either drug used alone would have 
Table 2 Details of drugs used in trials comparing treatments in acute severe asthma

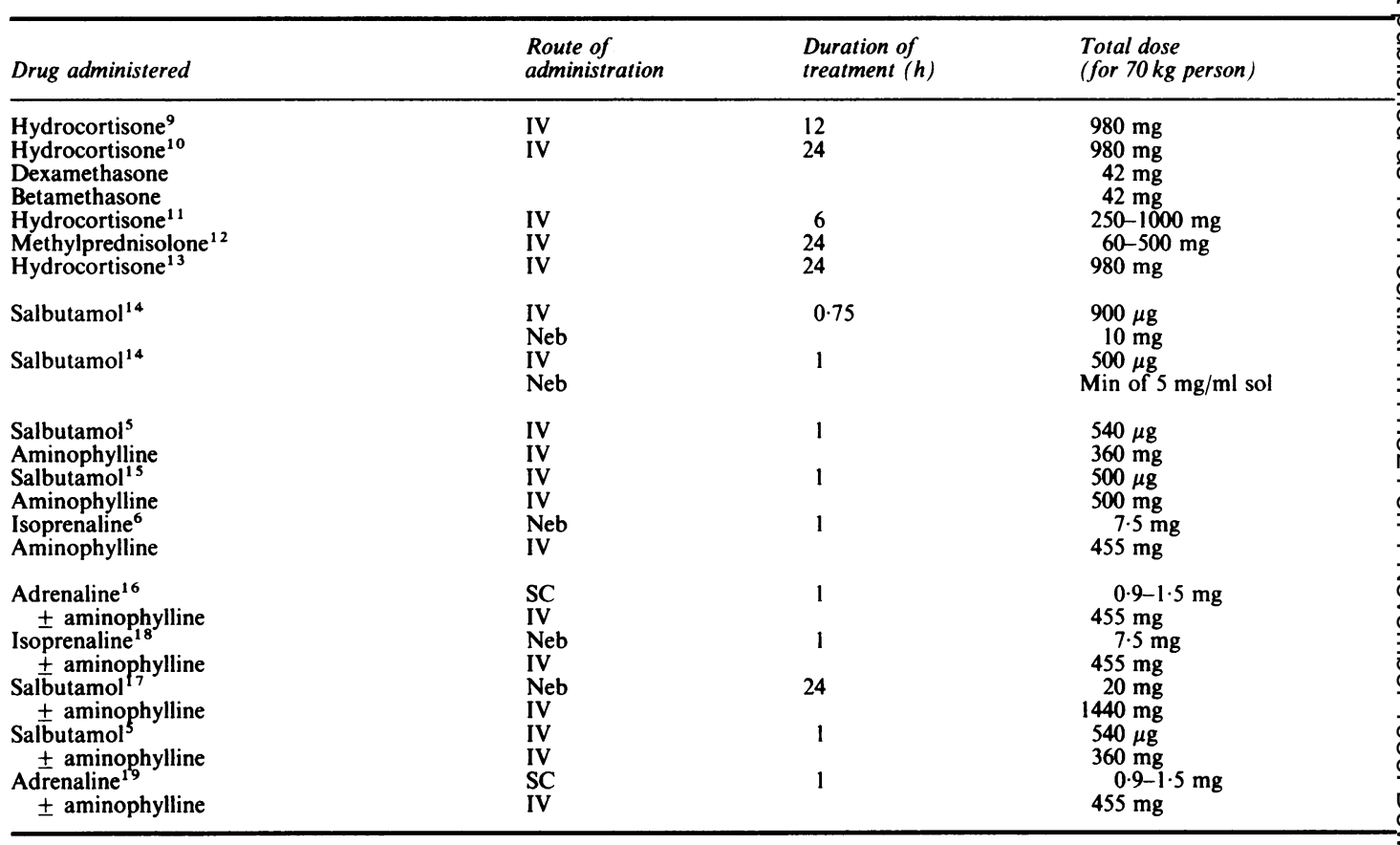

IV-intravenous; Neb-nebuliser; SC-subcutaneous; \pm -with and without.

given improved results equalling the effect of the combination is left unanswered by these studies.

Different doses of drug were used in the studies referred to and this makes direct comparisons of results difficult. In most cases, however, the doses used were comparable (table 2).

Future trials comparing treatment regimens in severe asthma need to take the type II error into account and negative studies in particular should include an analysis of the power attained in the study together with $95 \%$ confidence limits for the results. It is preferable to plan the requirements of a study in advance. The nomogram published by Altman may be used to calculate the power of a proposed study. ${ }^{8}$ An estimate of standard deviation of PEF or FEV 1 for the group to be studied is used to calculate the number of patients required to give a desired probability of detecting a clinically useful difference between treatments. Because patients recover from attacks of severe asthma at very different rates the increase in PEF varies widely from patient to patient and its standard deviation is considerable. For a study to reach a significant result therefore large numbers of patients need to be investigated. The power of a study may be increased by studying a more homogeneous population, such as those known to respond poorly to initial treatment.
I thank Dr Robert Newcombe for his help in the preparation of the manuscript.

\section{References}

1 Macdonald JB, Macdonald ET, Seaton A, Williams DA Asthma deaths in Cardiff 1963-74: 53 deaths in hospital. Br Med J 1976;ii:721-3.

2 Grant IWB. Are corticosteroids necessary in the treatment of severe acute asthma? Br J Dis Chest 1982, 76:125-9.

3 Hetzel MR, Clark TJH. Comparison of intravenous and? aerosol salbutamol. Br Med J 1976;ii:919.

4 Lawford P, Jones BJM, Milledge JS. Comparison or intravenous and nebulised salbutamol in initial treat ment of severe asthma. Br Med J 1978;i:84.

5 Evans WV, Monie RDH, Crummins J, Seaton A. Ami nophylline, salbutamol and combined intravenous infusions in acute severe asthma. Br J Dis Chesfi 1980;74:385-9.

6 Rossing TH, Fanta CH, Goldstein DH, et al. Emergencyo therapy of asthma: comparison of the acute effects of parenteral and inhaled sympathomimetics and infused? aminophylline. Am Rev Respir Dis 1980;122:365-71. T

7 Freiman JA, Chalmers TC, Smith H, et al. The importance of beta, the type II error and sample size ind the design and interpretation of the randomized con $\frac{\mathrm{O}}{\mathrm{Q}}$ trol trial. N Engl J Med 1978;299:690-4. 
8 Altman D. Statistics and ethics in medical research. $\mathrm{Br}$ Med J 1980;281:1336-8.

9 Kattan M, Gurwitz D, Levison H. Corticosteroids in status asthmaticus. J Pediat 1980;96:596-9.

10 Pierson WE, Bierman CW, Kelley VC. A double blind trial of corticosteroid therapy in status asthmaticus. Pediatrics 1974;54:282-8.

11 McFadden ER, Kiser R, deGroot WJ, et al. A controlled study of the effects of single doses of hydrocortisone on the resolution of acute attacks of asthma. Am J Med 1976;60:52-9.

12 Haskell RJ, Wong BM, Hansen JE. A double blind, randomised clinical trial of methylprednisolone in status asthmaticus. Arch Intern Med 1983;143:1324-7.

13 Fanta $\mathrm{CH}$, Rossing TH, McFadden ER. Glucocorticosteroids in acute asthma: a critical controlled trial. Am J Med 1983;74:845-51.

14 Bloomfield P, Carmichael J, Petrie GR, et al. Comparison of salbutamol given intravenously and by intermittant positive-pressure breathing in life- threatening asthma. $B r$ Med $J$ 1979; i:848-50.

15 Williams SJ, Parrish RW, Seaton A. Comparison of intravenous aminophylline and salbutamol in severe asthma. Br Med J 1975; ii:685.

16 Josephson GW, MacKenzie EJ, Lietman PS, et al. Emergency treatment of asthma. A comparison of two treatment regimens. JAMA 1979;242:639-43.

17 Johnson AJ, Spiro SG, Pidgeon J, et al. Intravenous infusion of salbutamol in severe acute asthma. $\mathrm{Br} \mathrm{Med}$ $J$ 1978;i:1013-5.

18 Fanta CH, Rossing TH, McFadden ER. Emergency room treatment of asthma. Relationships among therapeutic combinations, severity of obstruction and time course of response. Am J Med 1982;72:416-22.

19 Rossing TH, Fanta CH, McFadden ER, et al. A controlled trial of the use of single versus combined drug therapy in the treatment of acute episodes of asthma. Am Rev Respir Dis 1981;123:190-4.

20 Anonymous. Acute severe asthma [editorial]. Lancet 1981;i:313-4. 